\title{
MODELING OF AN E-BUSINESS SYSTEM
}

\author{
${ }^{1}$ Festim HALILI, ${ }^{2}$ Avni RUSTEMI \\ ${ }^{1,2}$ Department of Informatics ,University of Tetovo, UT, Tetovo, Macedonia \\ ${ }^{1}$ festim.halili@unite.edu.mk, ${ }^{2}$ avnirustemi11@gmail.com
}

\begin{abstract}
Always before we start creating or accessing a particular system, it is more than necessary to have a clearer picture of how to create, respectively, how to approach a certain system, in this case of a e-business system. It is much easier as for systems makers, as well as for ordinary users when they have before them a model of how to be accessed in such a system, because such a thing will orient users much easier to purchase products online through various systems on the one hand, but on the other hand it would help makers of systems create much easier such systems when they have already before them the right design. Modeling systems may be done in different ways, depending on the context of its research, but we in this paper we will use UML diagrams for modeling online system where we will make a comparison between UML diagrams and we will present each type of UML diagram in terms of customer access in online systems. Also using predictive techniques as CPM and PERT techniques in the paper we will present the main activities required for access to an online system by different users, and their graphic presentation and critical path finding, which shows the best way to approach such a system. There shall not fail and the description of business models and the introduction of some e-business models that are commonly used in practice in the days of today.
\end{abstract}

\section{Keywords}

UML diagrams, e-business models, CPM/PERT, e-commerce, e-business.

\section{I.INTRODUCTION}

In the days of today they are increasingly developing new models of e-business in order to advance and business growth of enterprise. Understanding the new business models and their designing are importantresearch issues that are not so well studied so far. Of course every manager and entrepreneur has an intuitive sense of how his business works, the logic that creates value, in other words the company's business model. But although this business model affects all important decisions of the enterprise, in many cases, managers and entrepreneurs are not able to communicate in a clear and simple way. And how can you decide on a particular issue or change it, if it is not clearly understood by the parties involved? For this reason it would be useful to think of different software tools that will enable business people to understand what's their business model and the essential elements of which it is composed [1]. What in fact is a business model it has various opinions and definitions. Next we present some of them. As explained by Petrovic in [2], a business model describes the logic of a "business system" for creating value, lying behind current processes. According to Rappa [3], a business model predicts how a company earns money by specifying where it is positioned in the value chain. His taxonomy consists of the nine forms of e-business models, which classifies companies in the midst of the nature of their proposal to their values or way of generating revenue (e.g. advertising, subscription or services model). Perhaps best known scheme of classification and definition of e-business models is that of Timmers [4]. According to him, a business model is an architecture for product, service and flow of information, a description of the different actors of the business and their roles, as well as a description of the potential benefits of these actors and finally a description of revenue sources.A business model is a description of the value that a company offers to one or several segments of customers and architecture firm and its network of partners to create, commercialize and send these values in order to generate benefits. Therefore, in general, we can say that an e-business model aims to address these issues:

- Novelties of products- what business the company is developing, innovation and value proposition of products offered in the market.

- Relationships with customers- who are customers of the company, in what way gives them products, and how builds strong relationships with them.

- Infrastructure Management - how the company efficiently performs infrastructure and logistics issues, with whom, and which types of virtual enterprises.

- $\quad$ Finances - which is the revenue model (transaction, subscription / membership, advertising) and cost model (cost of goods sold, operating expenses, sales and marketing, general and administrative)?

Through this paper we will not go into the details of creating new business models for companies, but will do modeling of approach to e-business system, or a system online, purchase method of online products and description of activities necessary to buy products online and in this regard will also present the CPM and PERT techniques such as predictive techniques but with a high degree of reliability, finding the best way to access these systems. Before proceeding with UML diagrams that will make modeling of a system online, in advance will make a brief description of some key concepts related to the topic we are addressing, respectively, the description of some e-business models that most used today in practice.

\section{E-BUSINESS MODELS}

There are many benefits that come from linking your business on the Web. An e-business can offer personalized service, high quality customer service and improved management of the supply chain. Amazon.com, eBay, Yahoo and others have 
helped to define the categories of industries and business models on the Web. Entrepreneurs starting from e-business should be aware of these models and how to apply them effectively. An e-business is defined as a company that has an online presence.E-businesses that have the ability to sell, trade, share and perform transactions on the Web can be considered e-commerce business. The combination of policy, actions, the company's technology and ideology define its business model. Some e-business models will explain below.

StoreFront Model- online storefront is an activity that is growing. StoreFront model is the first model that people think of when they hear the word e-business [5]. This model combines the processing of transactions, security, online payments and saving of information to enable merchants to sell their products on the web. This is a basic form of e-commerce where the buyer and seller interact directly. To realize a storefrontcommerce, merchants need to organize an online catalog of products,accept orders through the Web site that possess, to accept payment in a secure environment,send goods to customers and manage customer data (such as customer profiles).

Auction Model - Usually auction sites act as forums through which internet users can register and take the role of product provider or seller [5]. As a seller you have the opportunity to post an item you want to sell, the minimum price to ask for your product as well as the last time (deadline) to close the auction. Some websites allow you to add features, such as picture or a description of products. Example auction model is eBay. Although auction sites usually require a commission on sales, these sites are only a forum for buying and selling online. They are not included in the payment or distribution of products. Once the auction has ended, the seller and the buyer notified, and payment and the cost of the product is then placed between the two parties.

Portal Model- Portal sites give visitors an opportunity to find everything they want in a particular country [5]. They often offer news, sports and various kinds of information, and the ability to search the Web.When most people hear the word portal they immediately think of the so-called search engines. Other portals are more specific, offering a great deal of information relating to a single area of interest- these are called vertical portals. Portals help users collect information on the object for which they are looking.

Dynamic Pricing Models- Web has changed the way of doing business and consumers at the same time to participate in determining the manner of payment and delivery of products [5].In the past, customers needed to search every room for cheaper prices of products. Today, a few clicks via the Internet is all that you need to find the lowest price available for the product you want. Buying in large quantities is always pushing prices down, and now there are Web sites that allow you to buy products at very low prices as you are buying products in large quantities. Another strategy used by some businesses is to offer products and services free. Today forming different strategies partnership there are a large number of companies that offer very cheap prices of products (like buying wholesale), and even often thanks to the partnership between the companies enable the delivery of products free to the place where we live (as is the case with AliExpress, where most of the products are free shipping).

\section{III.MODELING OF AN ELECTRONIC SYSTEM FOR ONLINE BUSINESS}

Modeling a system can be made in different ways, depending on the nature of the system that is created. This paper will try to make modeling for online system using UML diagrams, which arestandard diagrams accepted around the world for modeling different systems (software). Starting from the simplest diagram which is Use Case diagram to the most complex, we will make graphical representation of all the diagrams in terms of accessing online systems.

\section{A. Use case diagrami}

Use case diagrams commonly referred to as behavioral diagrams that describe a set of actions (use Cases) that some systems can or should do in cooperation with one or more external users of the system (actors). Each use case must provide an observable result and valuable for actors or other stakeholders of the system. Use case diagram consists of 4 items:

Actor - in the use case diagram is an entity that performs a role in a given system. This can be a person, organization or an external system. A use case- is a feature or an action within the system. System- used to define the field of use case and drawn in the form of a rectangle. This is an optional but useful element when dealing with large systems. Package- is another optional element that is extremely useful in complex diagrams. The following is a use case diagram of a system for online access. 


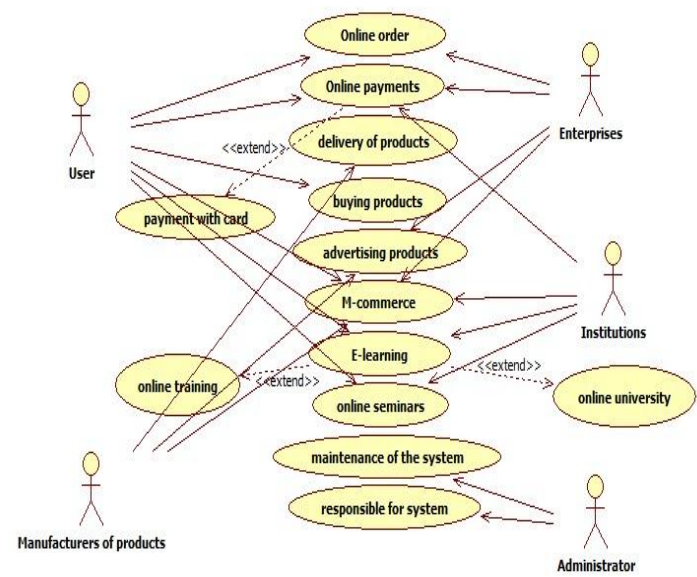

Fig1. Use case diagram for online system

\section{B. Activity diagram}

The logical place to start UML diagrams is based on the activity diagrams. Activity diagrams show the flow of control and representing a presentation in the form of diagrams, keeping a hierarchy of activities. Activities are capable of action which cross state into another state automatically after the action has finished. Activity diagram describes how activities are coordinated to provide a service, the events necessary to achieve an action, as the events in a use case associated with one another, as a collection of instances of coordinated to create a workflow for organization.

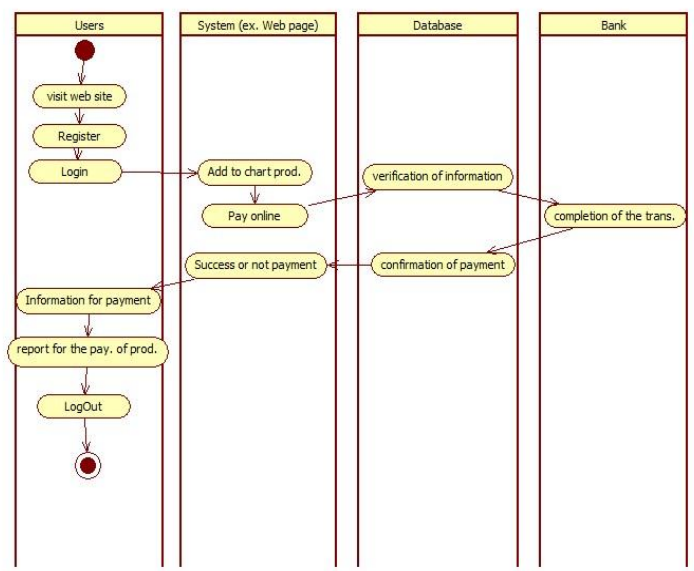

Fig2 . Activity diagram for online system

\section{Class diagram}

A class diagram is similar to the family tree. A class diagram consists of a set of classes and interfaces reflecting the main entities in the field of business system that is modeled, and the relationship between these classes and interfaces. Classes and interfaces of the diagram represent the tree family members and relations between classes are analogous to the relationship between family members. They are used to describe the types of objects in a system and relations. They shape the structure of classes and contents using design elements such as classes, packages and objects. They are used in most cases when it comes to design object-oriented software. Used to describe system classes and relations between them. 


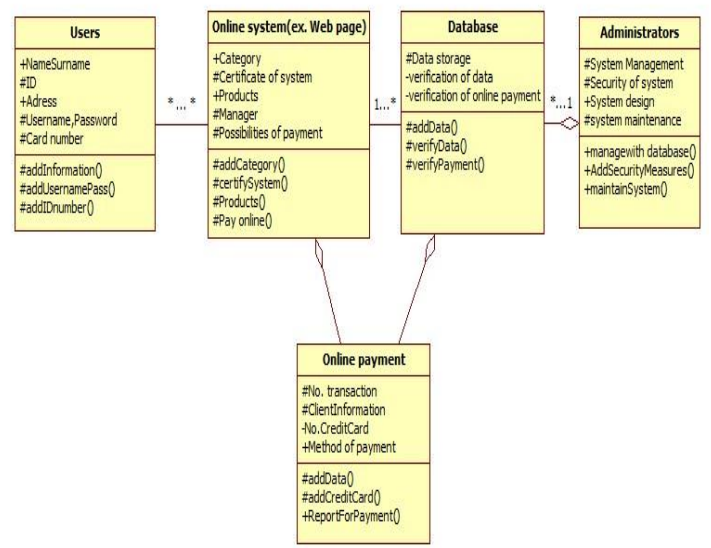

Fig 3 .Class diagram for online system

\section{Object diagram}

Although we define and design the classes, in concrete applications grades are not used directly, but the objects of these classes used for the execution of business logic. If these two types of diagrams are so similar, why is used object diagram? The class diagram does not show the interaction between them at the right time. Object diagrams show the connection between instant classes anddefined classes, and the connection between the objects in a logical form. Explain the smaller parts of the system in cases where the class system diagram is complex and recursive.

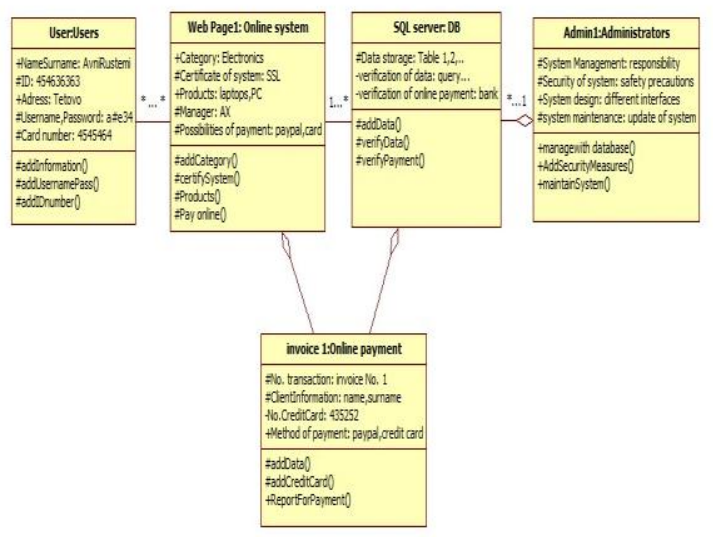

Fig 4 .Object diagram for online system

\section{E. Sequential diagram}

Sequence diagram describes the sequence of actions that appear in the system. Calling the methods in each object, and the directions in which the call (Invocation) is shown in the diagram appear sequential. Sequence diagram is twodimensional in nature. On the horizontal axis shows the life of the facility which representswhile on the vertical axis represents the sequence of creation or call for these objects.

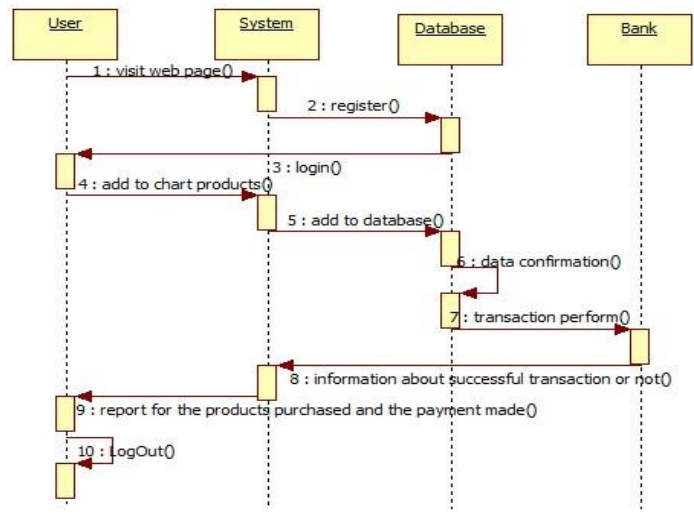

Fig5. Sequential diagram for online system 


\section{F. Diagram of collaboration}

The sequence diagram is dynamic and what is most important, it contains a directive time. Diagram of cooperation is very similar to the sequence diagram in terms of goal achievement; in other words, it shows the dynamic interaction system objects. The difference is in the fact that this diagram shows the objects and associations with other objects in the system, apart interoperability. Associations between objects are not represented in the diagram of Sequence! To identify the sequence of call facilities, a number placed next to each arrow. They show the interconnections between objects and sorting of messages that pass between them [7].

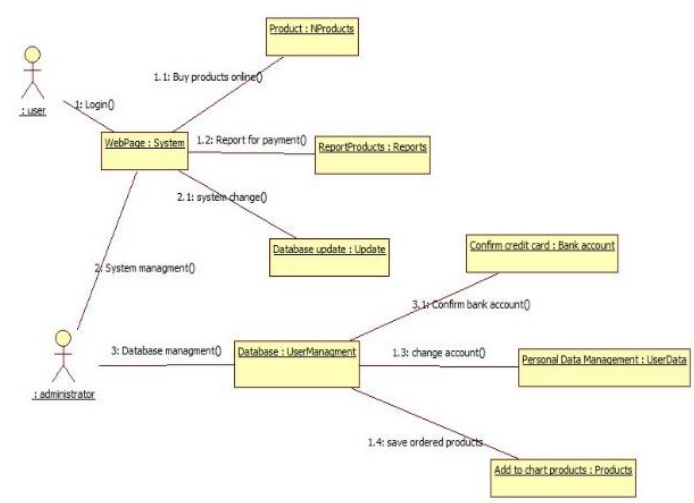

Fig6. Collaboration diagram for online system

\section{G. State diagram}

All diagrams mentioned so far arestatic diagrams, which means they help in visualized what elements of the complete system should be, but does not show anything for the following of any event that an item of system can have. Structural elements are used to describe static diagrams. During coding, it is necessary to understand the details of the object class status and transitions in different intervals during any event or action. The state diagrams (also called as graph state diagrams) are used to help developers better understand any complex or unusual function and flow of specialized business areas of the system.In short, the state diagrams identify the dynamic behavior of the whole system, or a subsystem, or even a single object in a system. This is done with the help of behavioral elements. It is important to note that having a state diagram for your application is not an obligation, but should be determined only on the basis of needs.

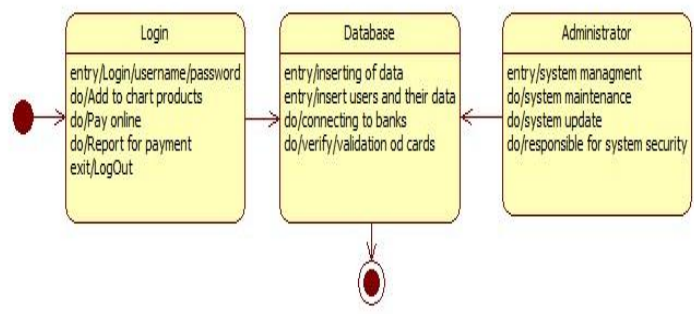

Fig7. State diagram for online system

\section{H. Distribution diagram}

Distribution diagram contains configuration of the execution time of the application elements. It is useful when a system is built and ready for distribution! Diagrams of distribution should start from when designing static formalized using class diagrams. Later distribution diagraminvolveand review all processes until the system is build.It is valuable to have description (visibility) how the distribution circumstances will be before the system built so that any distributions to be identified and resolved not to fail at the last minute. While components enable application functionality, distribution diagram elements enable required space to enable components to allow components to be executed [8]. 


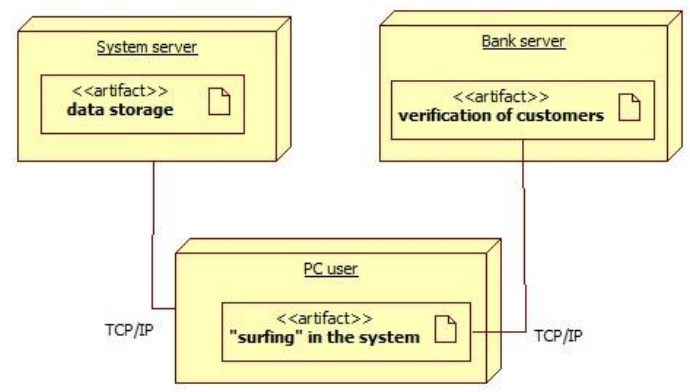

Fig8. Distribution diagram for online system

And finally we can give a summary of all diagrams more specifically what they represent. Use case diagram represents the system functions from the perspective of users. Sequence diagrams are a temporary representation of buildings and their interactions. Diagram of cooperation is spatial representation of objects, connections and interactions between them. The object diagram represents the objects and their relationships and cooperation correspond to the simplified diagrams that not represent transmitting messages. Class diagrams represent the static structure in terms of classes and relations between them. The state diagram represents the behavior of a class at the time of execution. Activity diagram represents the behavior of an operation as a set of actions. Component diagrams represent the physical components of an application and distribution diagram represents the distribution of components in separate parts of the hardware.

\section{CPM/PERT TECHNIQUES FOR ONLINE SYSTEM}

CPM / PERT is one of the techniques used to find the critical path, respectively finding the shortest path to the creation of a system. We can not begin creating a system without analyzing all of the functional and non-functional requirements of the system, the risks, the shortest path to the creation of the system with only one purpose, that of saving time, money and efficiency, which are the reasons and factors for success or failure of a business. Through this paper we will try to present the technique of CPM/PERT to an electronic business,but not for creating an online system (e-business system), but a process on how to conduct electronic business by user ordinary. We will try through a concrete example of user access to electronic business at the same time to do the elaboration of this important process during the construction of each system, but without going into its details. At first to introduce CPM / PERT we should have a list of activities necessary for accessing in such a system. In this aspect we would like to present what activities need to purchase a product online, as well as the dependence of activities which activity of which depends, the duration of those activities because such a thing is necessary for creating the CPM and PERT.

Table 1. List of electronic business activities

\begin{tabular}{|c|c|c|c|}
\hline Act. & Description & Dep. & $\begin{array}{l}\text { Duration } \\
\text { (min) }\end{array}$ \\
\hline A & Register & I & 3 \\
\hline B & Login & A & 1 \\
\hline $\mathrm{C}$ & $\begin{array}{l}\text { 'Surfing' through online } \\
\text { systems }\end{array}$ & I & 15 \\
\hline $\mathrm{D}$ & Buying products online & A & 15 \\
\hline $\mathrm{E}$ & $\begin{array}{c}\text { Connection database with } \\
\text { banks }\end{array}$ & $\mathrm{B}, \mathrm{C}$ & 1 \\
\hline $\mathrm{F}$ & $\begin{array}{l}\text { Checks on the user } \\
\text { account status }\end{array}$ & $\begin{array}{l}\mathrm{A}, \mathrm{C} \\
\mathrm{D}, \mathrm{E}\end{array}$ & 1 \\
\hline $\mathrm{G}$ & $\begin{array}{l}\text { Verification by DB for } \\
\text { successful purchase }\end{array}$ & $\mathrm{D}$ & 1 \\
\hline $\mathrm{H}$ & $\begin{array}{l}\text { Information in the system } \\
\text { for successful purchase }\end{array}$ & $\mathrm{E}, \mathrm{F}, \mathrm{G}$ & 1 \\
\hline I & $\begin{array}{l}\text { Report onpurchased } \\
\text { products }\end{array}$ & $\begin{array}{c}\mathrm{B}, \mathrm{D}, \\
\mathrm{H}\end{array}$ & 1 \\
\hline $\mathrm{J}$ & Logout & $\mathrm{B}, \mathrm{I}$ & 2 \\
\hline
\end{tabular}

From the table we see that the time required to complete activities is 41 hours. However, in some cases we can see that two or more activities can be carried out at the same time. That happens when such activities have the same "weight", respectively can be developed in parallel without having negative effects on the completion of the project,however for 
developers and those that implement the project is has great importance, because it accelerates the implementation of the project in the shortest time and at the same time enables the project to be "split" and to be developed from more groups of developers. The same applies when we access an online system where when buying products through online systems, some activities can be performed in parallel and such thing reduce time to purchase products online,which to large businesses plays a very important role.

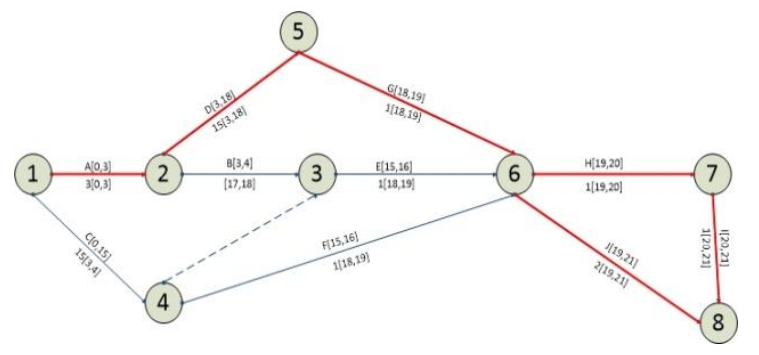

Fig9. Presentation of CPM for purchasing products online

The figure above indicates that to achieve the intended purpose, in this case buying products online, there are several ways, but from the figure, critical path is exactly the path A-D-G-H-I or A-D-G-J, of equal length of time of 21 hours [10]. Besides CPM almost similarly it is found the PERT technique, but we must have only an extension of the first table with some additional data, which are given in the following table:

Table2. Additional information about finding PERT

\begin{tabular}{|c|c|c|c|c|c|c|c|}
\hline Act & Dep. & $\begin{array}{c}\text { Opt. } \\
\text { time } \\
\text { a }\end{array}$ & $\begin{array}{c}\text { Most } \\
\text { likely } \\
\text { time }\end{array}$ & $\begin{array}{c}\text { Pes. } \\
\text { time } \\
(\mathrm{b})\end{array}$ & $\begin{array}{c}\text { Expect } \\
\cdot \text { value } \\
\mu\end{array}$ & $\begin{array}{c}\text { Var. } \\
\sigma 2\end{array}$ & $\begin{array}{c}\text { S. } \\
\text { Dev } \\
\delta\end{array}$ \\
\hline A & $/$ & 2 & 3 & 5 & 3.17 & 0.25 & 0.5 \\
\hline B & A & 1 & 1 & 2 & 0.67 & 0.03 & 0.17 \\
\hline C & $/$ & 12 & 15 & 20 & 15.33 & 1.78 & 1.33 \\
\hline D & A & 1 & 15 & 15 & 12.67 & 5.44 & 2.33 \\
\hline E & B,C & 1 & 1 & 3 & 1.33 & 0.11 & 0.33 \\
\hline F & D & 1 & 1 & 2 & 0.67 & 0.03 & 0.17 \\
\hline G & D & 1 & 1 & 3 & 1.33 & 0.11 & 0.33 \\
\hline H & E,F,G & 1 & 1 & 3 & 1.33 & 0.11 & 0.33 \\
\hline I & B,D,H & 1 & 1 & 3 & 1.33 & 0.11 & 0.33 \\
\hline J & B,I & 2 & 2 & 5 & 2.5 & 0.25 & 0.5 \\
\hline
\end{tabular}

For PERT we use mathematical formulas,i.e. the probability formulas for finding the time needed to calculate PERT.Among them the most important formulas are: $m=$ most likedtime, $a=$ optimistic time, pessimistic time $=b$, the expected value (TE) or

$$
\mu=(a+4 m+b) / 6
$$

variance or

$$
\sigma^{2}=((\mathbf{b}-\mathbf{a}) / 6)^{2},
$$

standard deviation or

$$
(\delta)=\operatorname{SQRT}(\mathbf{V})
$$

Below we present the PERT technique, based on specified formulasand from table 2 of buying products online. 


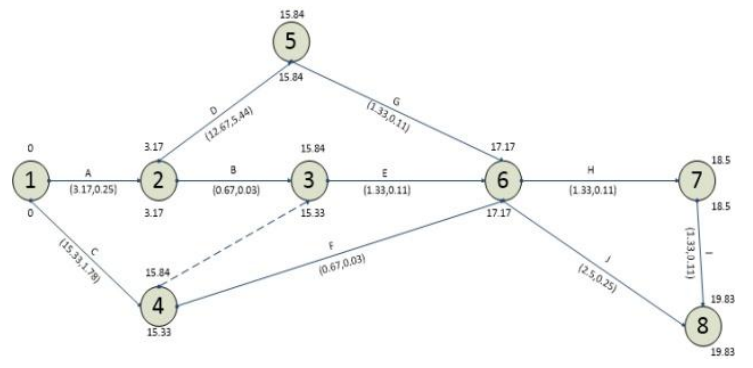

Fig10. Presentation of PERT for purchasing products online

\section{CONCLUSION}

The rapid development of computer science, in particular the rapid development of e-business enabled us to accomplish work easier than in the past. Thanks to this development we reach to learn online very easy. There are a number of web sites that offer a lot of different products where we as consumers need only to follow the main steps which are adapted (steps which we explained in this paper), and buy different products from different countries of the world, and also we have opportunities to acceptour products to the residential address. This is achieved thanks to the rapid development of internet on the one hand, but on the other hand thanks to the overwhelming interest in purchasing products online by the customers, because customers are precisely those who make a business to be lasting or not. Through our paper we tried to model the details of how it is done online interconnection of systems, who are the main actors involved in these systems, to do detailed design through all types of UML diagrams, with the only purpose that the readers to have more clearly the term "online systemand electronic business". Also we tried through explaining CPM / PERT techniques as predictive techniques but of particular importance, to find critical path and illustrate these techniques in the context of access to the online system. Also we tried to present some business models that are most frequently used by different enterprises. Electronic business although we can say that it has reached the pinnacle of its development, more and more it is being workedas much as possible to go furtherto advanceand more rapid development of electronic business, where traditional ways of buyingproducts, very quickly will disappear and everything will be done electronically, which will be profitable for both consumers as well as creators of various products.

\section{REFERENCES}

[1]Linder, J.C., Cantrell, S. (2001). Changing Business Models: Surveying the Landscape, Working Paper, Institute for Strategic Change, Accenture.

[2] Peterovic,O., Kittl, C.,Teksten, R.D. (2001). Developing Business Models for eBusiness, International Conference on Electronic Commerce 2001, Vienna, October 31 - November 4.

[3]Rappa, M. (2001). Managing the digital enterprise and business models on the Web, [online], http://ecommerce.ncsu.edu/business_models.html.

[4]Timmers, P. (1998). Business Models for Electronic Markets, Journal on Electronic Markets, 8 (2): 3-8.

[5] GolrouAbdollahi, Uwe Leimstoll (2011). A Classification for Business Model Types in Ecommerce, Proceedings of the Seventeenth Americas Conference on Information Systems, Detroit, Michigan August 4th-7th 2011.

[6] Randy Miller, Practical UML: A Hands- On Introduction for Developers, [online],http://edn.embarcadero.com/article/31863,Consulted: [06.05.2016].

[7] Bharath Padmanabhan (2012). Unified modeling language (UML) overview, EECS810- Principles of Software Engineering.

[8] Donald Bell (2003). UML basics: An introduction to the Unified Modeling Language.

[9] Jalam J. Dua, UML (Unified Modeling Language), [online], http://jdjua.com/uml.htm, Consulted: [06.05.2016].

[10] Frederick S. Hillier, Gerald J. Lieberman (2001). Introduction to operations research, Seventh Edition, Chapter 10: Project managment with PERT/CPM, ISBN: 0072321695.

[11] Rogelio acuña (2010). Analysis of project planning using CPM and PERT, 9th Annual University of HoustonDowntown Student Research Conference, Houston, TX, April 2010.

[12] John W. Chinneck (2015). Practical Optimization: a Gentle Introduction, Chapter 11: PERT for Project Planning and Scheduling, [online],

http://www.sce.carleton.ca/faculty/chinneck/po.html, Consulted: [06.05.2016].

[13]Vanhoucke M. (2012). Project managment with Dynamic scheduling, Chapter 2: The PERT/CPM technique, ISBN: 9783642251740 . 